\title{
Amorino (malato)
}

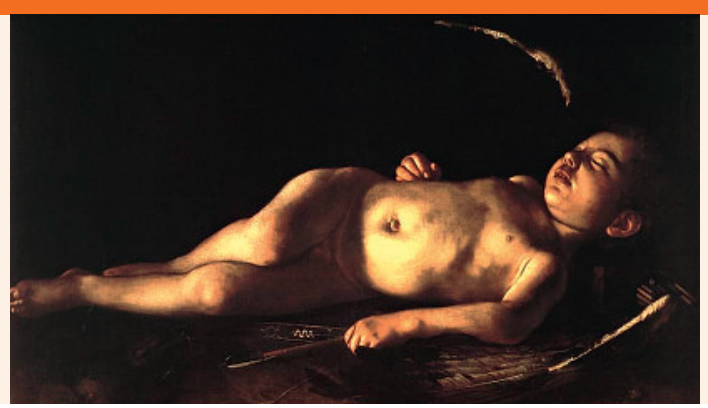

An jenem Freitagmorgen im Januar war der Himmel über dem Golf von Neapel von einer schwarzen Bläue, und obwohl die Sonne tief über dem silbrig glänzenden Meer stand, war es angenehm warm, die Leute sassen im Freien, genossen das helle Licht. Ich ging durch die via Piazza del Plebiscito bis zum Teatro San Carlo, erreichte gedämpftes Licht in der glasüberdachten, kreuzförmigen Galleria Umberto, ich schlendete entlang den teuren Boutiquen, bewunderte die Geschäftsauslagen, dann setzte ich mich vor ein Boulevard-Café. Hier war es, dass ich, in mein Notizbuch schreibend, von einem kleingewachsenen, halbwüchsigen Mädchen angesprochen wurde: «Monetu!» Ein Bettelkind, es hielt in der linken Hand einen leeren Pappbecher. Das Mädchen blieb vor meinem Tisch stehen, liess sich trotz abwehrender Gesten des Kellners - «vai, zingara, vai!» - nicht vertreiben, aber mich störte es nicht, ich sah pechschwarze, ungeordnete Haare, dunkle Augen, ein crèmefarbenes Gesicht mit breiter Stirn. Die Kleidung - durchlöcherter, knielanger, grauer Pullover, Jeans, ausgelatschte Sandalen - erinnerte unmissverständlich an das Elend

Ich würde eben über sie schreiben, meinte ich scherzend, und das schmale Mädchen, mit ihren schmutzigen Fingern den Buchstaben in meinem Notizbuch folgend, lachte und zeigte schwarze Zähne ohne Schmelz. Erst nachdem ich einige Münzen in den Pappbecher geworfen hatte, ging es, mehrmals als Dank in den Knien ihrer O-Beine einknickend, davon. Beim benachbarten Taxistand hinter der Oper konnte ich eine Horde Jugendlicher ausmachen, Kameraden meiner Bettlerin, alle gingen sie der gleichen Beschäftigung nach, und sie alle waren hager, ausgemergelt. Ganz hinten auf den Treppenstufen erkannte ich mehrere, noch jüngere Knaben, die, nur notdürftig in Decken eingewickelt und auf flachen Kartons liegend, mit offenen Augen zu schlafen schienen, sie wirkten präpariert, hatten grosse Bäuche, breite Köpfe, schwitzten in den Kopfhaaren, sie machten auf mich einen mitgenommenen, kaum noch halbwachen, kranken Eindruck.

Das eigentliche Ziel meines Neapelaufenthaltes aber war l'ultimo tempo di Caravaggio, die Ausstellung im Museo e Galleria Nazionali di Capodimonte, waren jene Bilder, die Caravaggio von 1606 bis zu seinem gewaltsamen Tod in Porto Ecole 1610 gemalt hat. Ich hatte, um zum ausserhalb der Stadt liegenden Museum zu gelangen, durch die dunklen Gassen von Spaccanapoli zu gehen, durch Gassenschluchten, vorbei an Palazzi, in denen in den untersten Etagen, in fensterlosen, eintürigen Verliessen, den sogenannten bassi, so, wie vor Hunderten von Jahren, noch immer die
Ärmsten wohnen. Noch immer, überlegte ich, kommt hier kein Sonnenlicht hin, niemals, hier herrscht jahraus, jahrein Dämmerung. Und hier traf ich wieder auf die bettelnden, hungernden Kinder, die, neben Müllhaufen sich hinkauernd, auf Beute lauerten. Ich war also froh, als ich das an schönster Lage über der Stadt thronende rote Schloss aus der Zeit der bourbonischen Restauration (um 1834) erreichte. Die vielen Schulklassen und die ununterbrochen läutenden Sirenen erschwerten den Zugang zu den wunderbaren Bildern des Meisters des italienischen Barocks, doch dass ich nun seine letzten Bilder, wie ich es mir vorgestellt und gewünscht hatte, in natura hier versammelt vorfand, versöhnte mich. Erschüttert stand ich vor den bestürzend realistischen Werken, denn die dargestellte Gewalt - Enthauptungen, Geisselungen, Züchtigungen - hat bis heute Gültigkeit. Und vor allem beim liegenden Cupido machte es mir Mühe, nicht in Tränen auszubrechen: Dieser amorino dormiente aus dem Jahre 1608, der schlafende, nackte Knabe von gelber Hautfarbe mit den abgeschnallten Engelsflügeln, die ihm als Schlafunterlage dienen, hat etwas Ergreifendes, und so stand ich lange Zeit vor dem durch eine Glasscheibe geschützten Bild.

Die Liebe, erst nach längerer Zeit begriff ich den Zusammenhang, den Grund meiner Erschütterung, schläft nicht nur, sondern sie ist krank, denn der Knabe hat einen grossen, froschartigen Bauch, einen ausladenden Thorax, verkürzte, verdickte Oberschenkel, er hat, so kam es mir vor, Doppelhöcker über den Sprunggelenken und einen auffällig quadratischen Kopf. Diese Feststellungen erlaubten mir die Zuordnung zur schweren Form kindlicher Rachitis. Natürlich gingen nun meine Gedanken zu den bettelnden Mädchen, zu den schlafenden Knaben und zu den bassi zurück. Dann, es war später Nachmittag geworden, machte ich mich wieder auf den Weg zurück zum Stadtzentrum. Dass mir, kurz vor der Oper, im engen Vico San Sepolcro, ein Begräbniszug entgegenkam, auf einem offenen Lieferwagen ein kleiner Sarg, auf Palmwedeln aufgesteckte Kränze, eine Gruppe schwarz gekleideter Menschen, zuhinterst gefolgt von einem mit weissen Rosen geschmückten Motorrad, verwirrte mich, aber mehr noch, dass ich meinte, meine kleine Bettlerin im Geleit des Sarges zu erkennen, doch auf ihr Winken, mit angedeuteter linker Hand in meine Richtung deutend, ging ich nicht ein, und schnell, ja fluchtartig, wandte ich mich zum Gehen. An diesem Abend verfärbte sich der Himmel über dem Golf von Neapel innert weniger Minuten von Dunkelblau zu Schwarz.
Dr. med. Enrico Danieli

Via ai Colli 22

CH-6648 Minusio

e.b.danieli@bluewin.ch

\section{Schwarz.}

